\title{
O ENGAJAMENTO COMO DISCURSO LITERÁRIO: UMA LEITURA DE ZERO ZERO ZERO, DE ROBERTO SAVIANO
}

\author{
Gisele Palmieri* \\ Universidade Federal do Rio de Janeiro
}

Um livro sobre a cocaína. É o que pode parecer, a princípio, a obra Zero Zero Zero (2014). Pelo menos é como os leitores mundo afora o definem. Lido por muitos como um relato jornalístico, cujo único objetivo é mostrar o funcionamento da indústria e do comércio - ilegal - do pó de cor branca e seu milionário faturamento digno de ser considerado a mola mestra da economia mundial, Zero Zero Zero é mais, muito mais que apenas informação sobre os mecanismos e faturamento do narcotráfico.

Considerado um romance investigativo pelas editoras que o publicaram, cada capítulo apresenta a história de uma ramificação criminosa latino-americana juntamente com a história de personagens que são peças importantes na engrenagem do narcotráfico, de maneira que, ao final da narrativa, o leitor tem, diante de si, montado o quebra-cabeças do funcionamento do narcotráfico em toda a América Latina. Tem-se em mãos quase que um dossiê. Os cartéis mexicanos, a guerrilha colombiana, os pushers, a máfia calabresa (Ndrangheta), Los Zeta, Mafija (máfia russa), o skipper, Comando Vermelho (na edição brasileira) e todos os grupos criminosos, produtores ou distribuidores da cocaína, estão ali representados. Muitos são os personagens envolvidos direta ou indiretamente com o mundo do narcotráfico. Sejam eles grandes boss da empresa das drogas ou mártires no combate ao tiranismo das grandes teias do poder paramilitar. Anônimos e famosos. Artistas e políticos. Chefes de família e chefes de clãs. Histórias reais que, romantizadas na narrativa, ganham ares de ficção, mas que na verdade tratam de protagonistas que emergiram às manchetes de

\section{Esta obra está licenciada sob uma Creative Commons - Atribuição 4.0}

\footnotetext{
* Doutoranda em Literatura Italiana na Universidade Federal do Rio de Janeiro. Possui mestrado em Teoria da Literatura e Literatura Comparada pela UERJ (2011) e é graduada em Letras - Português/Italiano pela UERJ. Email: gmnp80@yahoo.com.br.
} 
jornais ao longo desses anos de "guerra ao terror". Acompanhamos a vida de El Chapo, Don Salvador, Natalia Paris, Kiki Camarena, Tim Lopes (na edição brasileira), The Brainy Don, Christian Poveda, Griselda (La Madrina) e Sandra Ávila Beltrán (La Reina) como acompanhamos a vida de tantos outros emblemáticos personagens de ficção. Pessoas cujos destinos foram forjados pelo narcotráfico ou que se tornaram "lendas" do crime. O enredo leva para várias direções, criando um amálgama de gêneros narrativos. Apresenta-se ao leitor três distintas situações enunciativas: a história das vítimas, algozes e parceiros do narcotráfico; a investigação jornalística sobre as várias organizações narcotraficantes e, ainda, as reflexões de Roberto Saviano, momento em que seu lirismo pungente faz Zero Zero Zero se aproximar mais de um gênero puramente literário. Essa mescla entre ficção e não ficção, literatura e não literatura, objetividade e subjetividade criou uma interação crítica entre leitores de Saviano. "É um ensaio", dizem alguns, "é um trabalho investigativo", dizem outros, "não é literatura", ${ }^{1}$ falam outras tantas pessoas. Fiquemos com a definição do próprio autor em entrevista a um jornal português em outubro de 2014: “Quando me perguntam se o livro é um romance ou um ensaio, respondo: tem factos e tem uma reflexão pessoal."2 Alguns leitores também desmerecem a obra por conter nela muitas informações facilmente encontradas na internet. Fato é que Saviano serviu-se demasiadamene de fatos. O autor sofreu até acusação de ter plagiado trechos da Wikipedia pelo jornalista Michael Moynihan, do The Daily Beast, jornal norte-americano. Além disso, considera-se que, diferentemente de Gomorra (2006), obra que o alavancou como escritor, em Zero Zero Zero a tensão narrativa é mais fraca que no seu primeiro livro, que conta sua experiência ao se infiltrar na Camorra, máfia napolitana. Certo é que ler os fatos em um jornal ao invés de ler em sua obra não tem a mesma força catártica tão intrínseca ao texto literário. No livro do napolitano, os personagens ganham contornos dramáticos, evocando emotividade. O arquétipo do vilão, evidente num texto jornalístico, é posto em xeque na obra de Saviano. Conhecemos o lado humano dos grandes chefes narcos, homens que, mesmo capazes de realizar as maiores atrocidades, têm fé religiosa e amor à família. O julgamento maniqueísta cabe ao leitor.

Paralelo às peripécias de vidas que giram em torno do polêmico pó branco, há a reflexão e a expressão do autor/narrador/personagem desta atroz narrativa. Um dos capítulos "A ferocidade se aprende" -, destina a si mesmo, colocando-se como peça do jogo. Num diálogo metalinguístico com o leitor, indaga sobre o porquê escrever aquele livro. Por que

\footnotetext{
${ }^{1}$ Disponível em: http://www.lafeltrinelli.it/libri/roberto-saviano/zerozerozero/9788807030536 (comentários de leitores). Acesso em 23/06/2017.

${ }^{2}$ Disponível em: https://www.publico.pt/2014/10/10/culturaipsilon/noticia/ameacado-de-morte-a-unica-fuga-deroberto-saviano-e-para-a-frente-zero-zero-zero-e-sobre-cocaina-1672021. Acesso em 23/06/2017.
} 
investigar crimes, por que relatar e expor suas descobertas sobre assuntos tão indigestos e por isso mesmo evitados? Chega o autor a algumas possíveis respostas: "Você pode pensar que se ocupar de tudo isso seja uma maneira de redimir o mundo" (SAVIANO, 2014, cap. V) Após publicar Gomorra (2006) e ter a sua vida destruída - palavras do próprio autor - ao ter que passar a viver sob escolta policial 24 horas por dia, Saviano assume, com a publicação de Zero Zero Zero, o papel de escritor engajado. Extremamente engajado, diríamos. "Um herói nacional"3, disse o escritor italiano Umberto Eco.

O livro, além de ser um posicionamento crítico do autor, é um chamado de posicionamento da parte da população leiga e alheia às consequências do capitalismo. É a vontade de usar a palavra para expurgar a indignação face aos horrores permitidos por grandes grupos organizados e pequenas tribos cuja única ordem é a selvageria e brutalidade com a finalidade de proteger a produção e a rota das drogas. São atos ocultados ou superficializados graças à complacência covarde da política e da mídia. É uma narrativa pungente, posto que vai além do relato. Aprofunda os fatos noticiados na TV e nos jornais, revelando os mecanismos bárbaros por trás da máquina do tráfico de drogas, seu faturamento e a corajosa fragilidade de policiais, políticos, juízes e pessoas comuns que entram no embate com os criminosos. Tira a mordaça que aprisiona tantas vozes que se calam diante do terror latente naqueles que se veem impotentes diante dos grandes deuses do mercado da droga. "A palavra dá a você uma força muito superior à força que o seu corpo e a sua vida podem conter" diz Saviano (SAVIANO, 2014, cap. V). Não é apenas um livro sobre a cocaína. É sobre como a narrativa pode se sobrepor à paralisia diante do terror e tomar lugar na ação fraquejante e impotente contra o poder. Seu relato assume a forma de denúncia.

Impossível não se lembrar do seu conterrâneo Leonardo Sciascia, autor que também se utilizou da narrativa para denunciar a ação da máfia na Sicília. Roberto Saviano pode ser considerado um herdeiro de Leonardo Sciascia no que se refere aos objetivos das narrativas de ambos. Os dois sentem a necessidade de escrever sobre o crime, jogar luz sob o funcionamento oculto das máquinas criminosas. Quando Sciascia publicou Il giorno della civeta, em 1961, ficou conhecido como o primeiro escritor a falar sobre a máfia em uma narrativa, adotando um posicionamento crítico com intenção delatora, apesar de ser uma obra ficcional. Sciascia utilizou uma linguagem simples para fácil comunicação, um subgênero palatável às massas (romance policial) e uma objetividade no olhar sobre um assunto até então incômodo na Itália, com a finalidade de que sua obra tivesse o maior alcance possível.

3 Disponível em: http://www.albanianews.it/notizie/opinioni/718-intervista-a-roberto-saviano. Acesso em 20/06/2017.

Anu. Lit., Florianópolis, v. 22, n. 1, p. 188-191, 2017. ISSNe 2175-7917 
Quase meio século depois do autor siciliano, surge o napolitano Saviano, elevando os recursos estilísticos/linguísticos da obra literária ao mais alto grau de intenção informativa. Ao sabor das narrativas contemporâneas, Zero Zero Zero pode estar criando um gênero novo, posto que é uma mistura de autoficção, ensaio, romance investigativo, relato jornalístico e diário pessoal. Dessa vez, a linguagem simples, a intenção objetiva, a vontade de mais informar que romancear os fatos (pontos de contato entre ambos os autores) se mostra com maior agudeza. Consequência disso é a perseguição sofrida pelo escritor que, ameaçado de morte pela Camorra, foi obrigado a deixar seu país (uma espécie de Salman Rushdie italiano, segundo o New York Times). Na figura de Roberto Saviano, a imagem do escritor impegnato (engajado), surgida na Itália nos anos 40, após a Segunda guerra mundial, é atualizada, posto que evoluída de acordo com os anseios do leitor pós-moderno.

NOTA DE ESCLARECIMENTO: Convém esclarecer ao leitor que, embora a resenha tenha sido feita a partir da leitura da edição original, em italiano, publicada pela editora Feltrinelli em 2014, há na edição traduzida para o português pela editora Companhia das Letras (em 2014) um capítulo chamado "Caldeirão do Diabo", referente ao Brasil, que inexiste na edição original estudada. Este capítulo foi escrito pelos tradutores com o consentimento e auxílio de Roberto Saviano, fato esclarecido pelo autor em "Agradecimentos".

\section{Referências}

Albânia News. Intervista a Roberto Saviano. Disponível em: $<$ http://www.albanianews.it/notizie/opinioni/718-intervista-a-roberto-saviano $>$. Acesso em: $20 / 06 / 2017$.

La Feltrinelli. Recensioni. Disponível em: $<$ http://www.lafeltrinelli.it/libri/robertosaviano/zerozerozero/9788807030536>. Acesso em: 20/06/2017.

MOURA, Paulo. A única saída de Roberto Saviano é para frente. Zero Zero Zero é sobre a cocaína.

Disponível

em:

$<\underline{\text { https://www.publico.pt/2014/10/10/culturaipsilon/noticia/ameacado-de-morte-a-unica-fuga- }}$ de-roberto-saviano-e-para-a-frente-zero-zero-zero-e-sobre-cocaina-1672021>. Acesso em 20/06/2017.

SAVIANO, Roberto. Zero Zero Zero. Milano: Feltrinelli, 2014, edição Kindle.

Zero Zero Zero. Trad. de Federico Carotti, Maurício Santana Dias, Joana Angélica D’Avila Melo e Marcello Lino. Rio de Janeiro: Companhia das Letras, 2014, edição Kindle.

Recebido: $23 / 04 / 2017$

Aceito: 18/06/2017

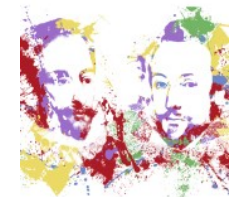

